\title{
Experimental Study and Modeling of Fouling in Immersed Membrane Bioreactor Operating in Constant Pressure Filtration
}

\author{
Mostafa Hosseinzadeh, Mohammad Reza Mehrnia, and Navid Mostoufi \\ School of Chemical Engineering, College of Engineering, University of Tehran, P.O. Box 11155-4563, Tehran, Iran \\ Correspondence should be addressed to Mohammad Reza Mehrnia; mmehrnia@ut.ac.ir
}

Received 5 December 2012; Revised 3 April 2013; Accepted 12 April 2013

Academic Editor: Xiaosheng Qin

Copyright ( 2013 Mostafa Hosseinzadeh et al. This is an open access article distributed under the Creative Commons Attribution License, which permits unrestricted use, distribution, and reproduction in any medium, provided the original work is properly cited.

\begin{abstract}
A new mathematical model is proposed based on filtration mechanisms for the prediction of fouling in airlift immersed membrane bioreactors (iMBRs). The cake formation on the membrane surface through constant pressure filtration process in the iMBR was explained by a proposed cake filtration mechanism which assumes that no particle enters the pores when forming the cake layer on the membrane surface. The cake porosity reduction due to diffusion of particles was described by an intermediate blocking mechanism. Experimental study of fouling was also performed in a lab-scale airlift flat-sheet iMBR operating at constant vacuum. The mixed liquor suspended solid (MLSS) concentration was changed within the range of 5000 to $15000 \mathrm{mg} / \mathrm{L}$, while the superficial air velocity was varied between 32 and $128 \mathrm{~m}^{3} / \mathrm{m}^{2} / \mathrm{h}$. The presented model includes two parameters, that is, ultimate filtration resistance and initial rate of cake formation. The effect of the MLSS concentration and superficial air velocity on the parameters of the proposed model was studied. The results obtained from the model demonstrated that the ultimate filtration resistance and the initial rate of cake formation are more sensitive to the aeration rate at lower superficial velocities. It was also shown that the ultimate filtration resistance has a linear relation with MLSS concentration. A good agreement exists between the results of the model and the experimental data. The proposed model also showed a better compatibility with the experimental data compared to other fouling models available in the literature.
\end{abstract}

\section{Introduction}

Membrane bioreactor (MBR) is a relatively new technology that is widely used for wastewater treatment [1-3]. An MBR has many advantages, including high removal rate of chemical oxygen demand (COD), high efficiency of the treatment, high concentration of biomass, reduced demanded area, and sludge production [4-8]. Fouling is a crucial problem in MBRs which takes place due to the accumulation of particles on the membrane surface. This phenomenon in the immersed membrane bioreactor (iMBR) occurs both internally (pore blocking) and externally (cake formation). Biomass concentration and aeration rate are two important parameters which affect fouling in iMBR systems. Although high concentration of biomass improves the treatment efficiency and reduces the space needed for the treatment process, it leads to a higher fouling rate. On the other hand, high aeration rate decreases the fouling and provides oxygen required by microorganisms.
However, it accounts for more than $70 \%$ of the total energy consumption in wastewater treatment plants, especially in MBRs [8-13].

Modeling is essential in the design of processes and especially in predicting the performance of a system. Many researchers have offered several models to describe fouling phenomena in the MBR and considered different operating parameters in their model [14-16]. Lee et al. [17] proposed a simple model based on activated sludge models (ASMs) to predict the total hydraulic resistance in MBRs. However, their model cannot predict the fouling with enough accuracy in the iMBR, and specific experimental verification is necessary for general use of such model $[6,14,18]$. Moreover, it has some shortcomings due to the biological model used in their approach [19]. Therefore, other models such as fractal permeation, empirical hydrodynamic, and resistance in series were introduced by other researchers [20-22]. The fractal permeation model, presented by Meng et al. [20], has fewer 
parameters and was indirectly validated for the prediction of cake permeability. However, this model does not show how operational parameters affect the filtration resistance [14].

Empirical hydrodynamic models are useful for illustrating hydrodynamic effects on the fouling process [21]. Nevertheless, such models may not be suitable for design and operational purposes [14]. Sectional resistance models are only able to capture general trends and are not appropriate for description of membrane fouling phenomena [14, 22]. Common filtration models divide the total hydraulic resistance, based on Hermia's theory, into cake formation, complete blocking, intermediate blocking, and standard blocking [23]. Cake filtration model is based on the fouling occurring by the deposition of suspended solids on the membrane surface. Pore blockage is divided into three parts: complete pore blockage, intermediate pore blockage, and standard pore blockage which correspond to the portion of particles blocking the pores completely, particles with specific probability to block a pore, and particles deposited inside the pores and reduced the diameter of pores, respectively. Drews et al. [24] studied these models and concluded that none of them can individually properly predict the fouling in an MBR. In addition, they developed the automated mechanism recognition (AMR) by the combination of these models in order to describe the fouling tendency.

In general, fouling is a very complex phenomenon which is affected by several biological and hydrodynamic factors [18, 25]. The mixed liquor suspended solid (MLSS) concentration is expected to be the efficient biochemical parameters on the membrane fouling [26] and the aeration as an operating parameter has a critical role in the formation of cake layer and its architecture [27]. In this study, the effect of MLSS concentration and aeration intensity on fouling in the iMBR was examined. The main objective of this study was to experimentally evaluate the membrane fouling in the iMBR and to theoretically develop a simple model for prediction of membrane fouling at constant pressure operation of iMBR.

\section{Modeling}

There exist mechanistic models which calculate filtration resistance in the iMBR sMBR. However, they have not yet been used for process control. Therefore, it can be proposed to develop a new model based on the mechanism of fouling. In the filtration process, Darcy's law describes the relation between permeate flux $(J)$ and resistance $(R)$ through the following equation:

$$
J=\frac{\Delta P}{\mu R} .
$$

Hermia's theory describes the filtration process by [23]

$$
-\frac{d J}{d t}=k\left(J-J^{*}\right) J^{n-2}
$$

where $J^{*}$ is considered to be the limit value of the permeate flux attained at the steady-state conditions [28]. In the constant pressure filtration process, the flux drastically reduces initially due to the rapid settling of suspended solids on the membrane surface, and a cake layer is formed. In this case, particles do not enter the membrane pores but form a biofilm layer on the membrane surface. The cake filtration model can be obtained by putting $n=0$ and $J^{*}=0$ in (2) [28]. Combining (1) and (2) results in the following equation for the cake filtration mechanism:

$$
R \frac{d R}{d t}=k\left(\frac{\Delta P}{\mu}\right)^{2},
$$

where $k$ is defined as follows when main process mechanism is cake filtration [29]:

$$
k=\frac{\alpha \rho \phi}{F^{2} R_{m} J_{0}(1-m \phi)},
$$

in which $F$ is an active opening surface of the filtration area and can change with time, while the specific resistance of filtration cake $(\alpha)$, filtrate density $(\rho)$, shape factor of suspended solid $(\phi)$, and ratio of the mass of humid cake to dry cake $(m)$ is constant.

The cake filtration model proposed by Hermia was derived for dead-end filtration condition [30], and it should be modified for cross-flow filtration systems such as iMBR. In iMBRs, the cake layer, formed on the surface of membrane, develops a dynamic biofilm layer. Its structure changes biologically due to underneath anoxic layer [31]. Also, the penetration of colloids and soluble extracellular polymeric substances (EPS) into the cake layer results in the reduction of the porosity of the biofilm $[31,32]$. Thus, in cross-flow models, the constant $k$ in (3) should be considered a variable through the filtration process in the iMBR. It can be suggested that a new biofilm layer forms the existing deposited biofilm. Thus, the opening pores on the membrane surface area $(F)$ change through the filtration process in the iMBR. These changes can be described by the intermediate blocking mechanism. It seems that a new biofilm layer is formed on the existing deposited biofilm. In other words, suspended particles settle on the cellular structure and alter the porosity of the cake layer formed on the membrane surface, leading to a reduction in filtration flux [20]. Therefore, the active surface of filtration decreases linearly with time which is shown by [33]

$$
\frac{F}{F_{0}}=1+C_{1} t
$$

where $F_{0}$ is the area of the membrane surface before the contact of the activated sludge. Also, according to (1),

$$
J_{0} R_{m}=\frac{\Delta P}{\mu} .
$$

Combining (3), (4), (5), and (6) results in

$$
R \frac{d R}{d t}=\frac{\alpha \rho \phi \Delta P}{\mu F_{0}^{2}(1-m \phi)\left(1+C_{1} t\right)^{2}} .
$$

According to (7), if the system operates for a long time, variation of the fouling intensity becomes insignificant, and the permeate flow rate reaches a constant value. 
Equation (7) can be rewritten as

$$
\frac{1}{J^{2}}-\frac{1}{J_{0}^{2}}=\left(\frac{\mu R_{\infty}}{\Delta P}\right)^{2}\left(\frac{t}{t+\left(R_{\infty} / r_{R}\right)}\right) .
$$

This equation has only two parameters, $r_{R}$ and $R_{\infty}$ :

$$
\begin{gathered}
R_{\infty}=\sqrt{\frac{2 \alpha \rho \phi R_{m} J_{0}}{C_{1} F_{0}^{2}(1-m \phi)}}, \\
r_{R}=\frac{\alpha \rho \phi J_{0}}{F_{0}^{2}(1-m \phi)} .
\end{gathered}
$$

The parameter $r_{R}$ is the initial rate of cake formation; that is,

$$
\left.\frac{\partial R}{\partial t}\right|_{t=0}=r_{R}
$$

This value indicates the tendency of the system to form cake on the surface of membrane at the start of filtration. Also, $R_{\infty}$ is the ultimate filtration resistance; that is,

$$
\lim _{t \rightarrow \infty} R=R_{\infty}
$$

This parameter illustrates the resistance of the formed cake that the system would eventually reach due to membrane fouling.

\section{Experiments}

A flat sheet chlorinated polyethylene membrane (KUBOTA Membrane Europe Ltd., Porlock, UK) with an area of $0.11 \mathrm{~m}^{2}$ and a mean pore size of $0.45 \mu \mathrm{m}$ was used in the experiments. The biomass was from a municipal wastewater treatment plant in west of Tehran, Iran. The experiments were carried out in an airlift iMBR, the schematic of which is shown in Figure 1. The bioreactor was $55 \mathrm{~cm}$ high, $23 \mathrm{~cm}$ long, and $21 \mathrm{~cm}$ width in which the membrane was submerged. Two baffles were placed at both sides of the membrane with $4 \mathrm{~cm}$ distance. The driving force for filtration was created by vacuum. Fouling starts to form on the membrane surface when the flux and the permeability of the membrane begin to decrease at constant pressure filtration condition. The permeate flow rate was measured by a digital balance. MLSS and COD were measured according to standard methods [34].

In all experiments, the system was fed by a synthetic influent, glucose, ammonium nitrate, and potassium phosphate which are the sources of carbon, nitrogen, and phosphorus, respectively, with a ratio of $100 / 5 / 1$ for COD/N/P. The COD of feed was $1000 \mathrm{mg} / \mathrm{L}$. During the experiments, temperature, $\mathrm{pH}$, volume of activated sludge in the bioreactor, and transmembrane pressure (TMP) were kept constant as $25^{\circ} \mathrm{C}$, $7.5 \pm 0.5,20 \mathrm{~L}$, and $20-40 \mathrm{kPa}$, respectively. The tests were carried out at four different aeration intensities (32, 64, 96, and $128 \mathrm{~m}^{3} / \mathrm{m}^{2} / \mathrm{hr}$ ) and at four MLSS concentrations (5000, $8000,12000$, and $15000 \mathrm{mg} / \mathrm{L})$. The mean hydraulic retention time (HRT) of the system was about 12 hours. The solids retention time (SRT) of the system was infinite. The activated

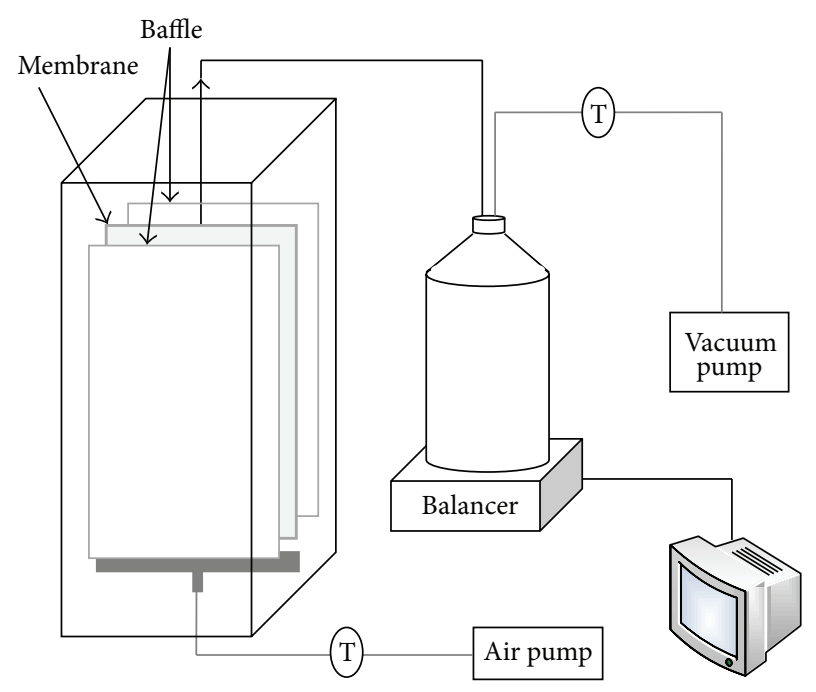

FIGURE 1: Schematics of the experimental setup.

sludge suspensions were acclimatized for two weeks with the same operating conditions of the iMBR. Each test run was performed for analysis of fouling mechanism after two weeks in order to reach the same biological steady state.

\section{Results and Discussion}

At the initial steps of operation, the efficiency of removal of COD was $90 \pm 2 \%$. Then, this value increased and reached to more than $95 \%$ after $30 \mathrm{~min}$ of operation, followed by a plateau in the rest of the experiment. The steady-state COD removal efficiency of the iMBR was about $96 \%$. When the cake layer was gradually formed on the membrane surface, the increase in the permeate flux and the decrease in the HRT occurred with the operation time. Therefore, the biomass had more time to remove COD and, consequently, enhanced the removal efficiency. Furthermore, the cake layer acted as a second biological barrier in removing COD. This is in agreement with previous reports which showed that the cake layer can affect COD removal in the iMBR [35].

Figure 2 illustrates application of Hermia's model (2) to different experimental conditions. By assumption that $J^{*}=$ 0 , the slop of the line of $\operatorname{Ln}(-d J / d t)$ against $\operatorname{Ln}(J)$ is equal to $3-n$ which specifies the fouling mechanism. This figure shows that $n$ is close to zero (from -0.0713 to 0.1289 ) at the initial steps of the processes in all experiments. Therefore, the cake filtration mechanism is the dominant mechanism at the startup of the processes. However, the governing mechanism changes during the operation. As indicated in (11), if the system operates for a long time, the variation of the fouling intensity becomes insignificant, and the permeate flow rate reaches a stable value. In all cases, the model was fitted to the experimental data of this work with a correlation coefficient of greater than 0.97. Calculated model parameters for all tests and the corresponding correlation coefficients are listed in Table 1.

In order to test the ability of the model to predict the fouling intensity, model parameters, $R_{\infty}$ and $r_{R}$, were 


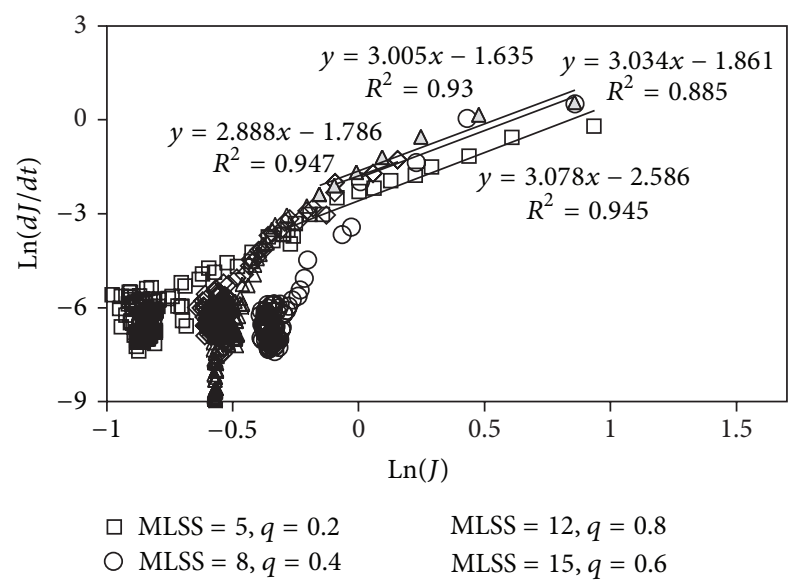

Figure 2: Experiments data agreements with Hermia's model $\left(\mathrm{TMP}=40 \mathrm{kPa}\right.$, MLSS $=5000 \mathrm{mg} / \mathrm{L}$, and $\left.q=128 \mathrm{~m}^{3} / \mathrm{m}^{2} / \mathrm{hr}\right)$.

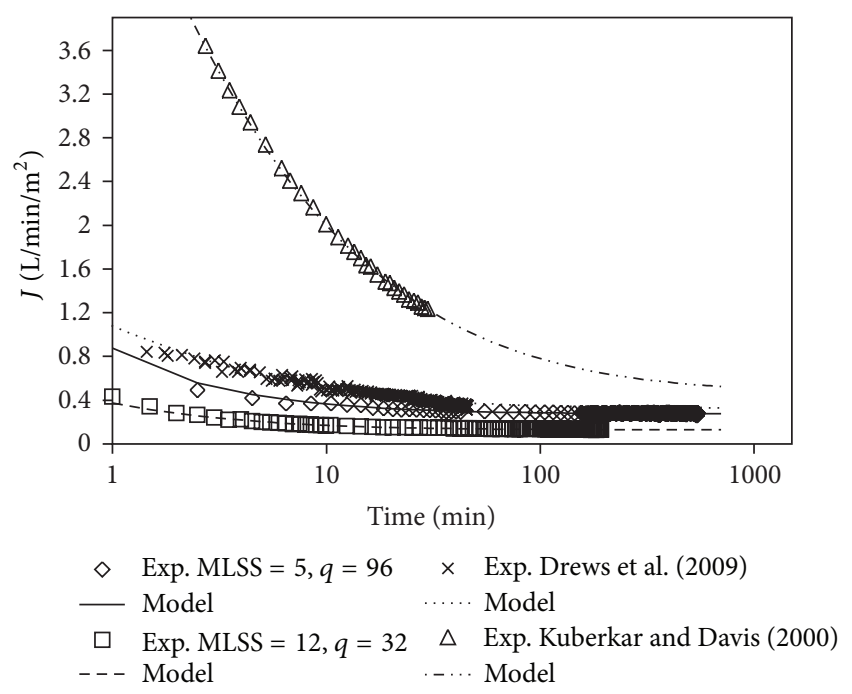

FIGURE 3: Experimental and predicted flux against time.

obtained based on the data from the first hour of the experiments. Then, these parameters were used for predicting the fouling in the rest of operation. Figure 3 shows the presented model prediction for the data of this research and other researchers for the iMBR operating at constant TMP using the flat sheet membrane $[24,36]$. This figure demonstrates that the proposed model predicts the liquid flux through the membrane at long time as well as short time operation even though they had different operation conditions (such as MLSS, aeration intensity, HRT, and SRT). Therefore, this model can be used for the prediction of biofouling in flatsheet iMBR systems operating at constant TMP.

Fouling models based on various mechanisms are shown in Table $2[23,24]$. Figure 4 demonstrates a comparison between the performances of these models with the model developed in this work. As can be seen in this figure, previous models cannot predict the fouling in the iMBR properly since they are based on the theories that cannot explain the fouling in iMBRs. However, the model developed in this work is
TABLE 1: Model parameters at various MLSS concentration and superficial velocity, calculated based on the first hour of the fouling process.

\begin{tabular}{lccccc}
\hline $\begin{array}{l}\text { Aeration } \\
\text { intensity } \\
\left(\mathrm{m}^{3} / \mathrm{m}^{2} / \mathrm{hr}\right)\end{array}$ & $\begin{array}{c}\text { MLSS } \\
\text { concentration } \\
(\mathrm{mg} / \mathrm{L})\end{array}$ & 5000 & 8000 & 12000 & 15000 \\
\hline 32 & $R_{\infty}\left[10^{12} / \mathrm{m}\right]$ & 2.2227 & 2.4900 & 2.1968 & 2.5889 \\
& $r_{R}\left[10^{12} / \mathrm{m} / \mathrm{min}\right]$ & 0.2286 & 0.5619 & 0.7409 & 0.8916 \\
& $R^{2}$ & 0.9649 & 0.9677 & 0.9846 & 0.9668 \\
\hline \multirow{4}{*}{64} & $R_{\infty}\left[10^{12} / \mathrm{m}\right]$ & 1.3363 & 1.5513 & 1.4839 & 1.6511 \\
& $r_{R}\left[10^{12} / \mathrm{m} / \mathrm{min}\right]$ & 0.1862 & 0.4407 & 0.7267 & 0.8400 \\
& $R^{2}$ & 0.9799 & 0.9816 & 0.9828 & 0.9838 \\
\hline \multirow{4}{*}{6} & $R_{\infty}\left[10^{12} / \mathrm{m}\right]$ & 1.0365 & 1.2646 & 1.3161 & 1.4391 \\
& $r_{R}\left[10^{12} / \mathrm{m} / \mathrm{min}\right]$ & 0.1577 & 0.3429 & 0.5790 & 0.9943 \\
& $R^{2}$ & 0.9856 & 0.9872 & 0.9861 & 0.9844 \\
\hline \multirow{4}{*}{128} & $R_{\infty}\left[10^{12} / \mathrm{m}\right]$ & 0.8218 & 1.0519 & 1.1765 & 1.3108 \\
& $r_{R}\left[10^{12} / \mathrm{m} / \mathrm{min}\right]$ & 0.1359 & 0.3157 & 0.4478 & 0.6711 \\
& $R^{2}$ & 0.9797 & 0.9855 & 0.981 & 0.9885 \\
\hline
\end{tabular}

TABLE 2: Convectional models of fouling [23, 24].

\begin{tabular}{|c|c|c|c|}
\hline No. & Theory & Equation & $R^{2}$ \\
\hline E1 & $\begin{array}{c}\text { Cake } \\
\text { filtration }\end{array}$ & $\frac{Q_{0}}{Q}=1+\frac{a X}{\rho A R_{m}} V(t)-\frac{a Q_{\infty}}{A R_{m}}$ & 0.950 \\
\hline E2 & $\begin{array}{l}\text { Standard } \\
\text { blocking }\end{array}$ & $\frac{t}{V(t)}=\frac{1}{Q_{0}}+\frac{\Delta P \sigma t}{\mu A Q_{0} R_{m}}$ & 0.904 \\
\hline E3 & $\begin{array}{c}\text { Intermediate } \\
\text { blocking }\end{array}$ & $\frac{1}{Q}=\frac{1}{Q_{0}}+\frac{\Delta P \sigma t}{\mu Q_{0} R_{m}}$ & 0.781 \\
\hline E4 & $\begin{array}{l}\text { Complete } \\
\text { blocking }\end{array}$ & $Q=Q_{0}-\frac{\Delta P \sigma V(t)}{\mu R_{m}}$ & 0.769 \\
\hline
\end{tabular}

in good agreement with the experimental data. The fitted parameters of the models, shown in Table 2, were calculated from the data of the first hour of the fouling process. The filtration resistance can be attributed to formation of cake on the membrane surface which is a function of permeate flux as well as time. This function can be described by cake filtration and intermediate blocking filtration mechanisms. The cake initially forms on the surface of the membrane and then reaches the steady-state condition. Initial formation of cake can be defined by $r_{R}$, and the steady-state condition can be represented by $R_{\infty}$.

The constants of the model obtained from the first hours of the filtration can appropriately predict the membrane fouling intensity of flat-sheet iMBRs in the constant pressure processes. The proposed model has two constants, that is, initial rate of cake formation $\left(r_{R}\right)$ and ultimate filtration resistance $\left(R_{\infty}\right)$, related to cake formation and standard blocking mechanisms, respectively. Since the MLSS concentration and the superficial gas velocity are accepted to be the two major operating parameters influencing the membrane fouling, the effect of MLSS concentration and superficial air velocity on the parameters of the proposed model was evaluated. 


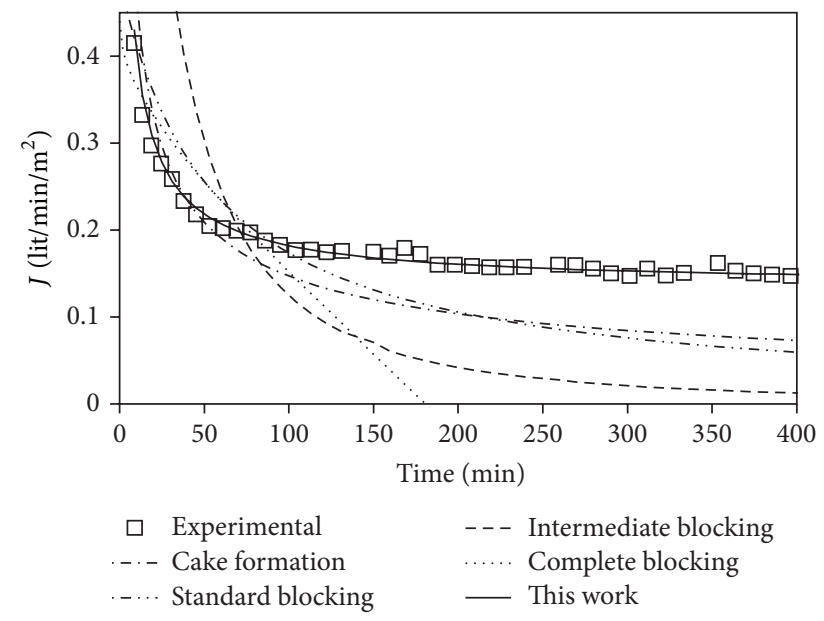

Figure 4: Comparison between convectional models of fouling with the model presented in this work (TMP $=40 \mathrm{kPa}$, MLSS $=$ $12000 \mathrm{mg} / \mathrm{L}$, and $\left.q=32 \mathrm{~m}^{3} / \mathrm{m}^{2} / \mathrm{hr}\right)$.

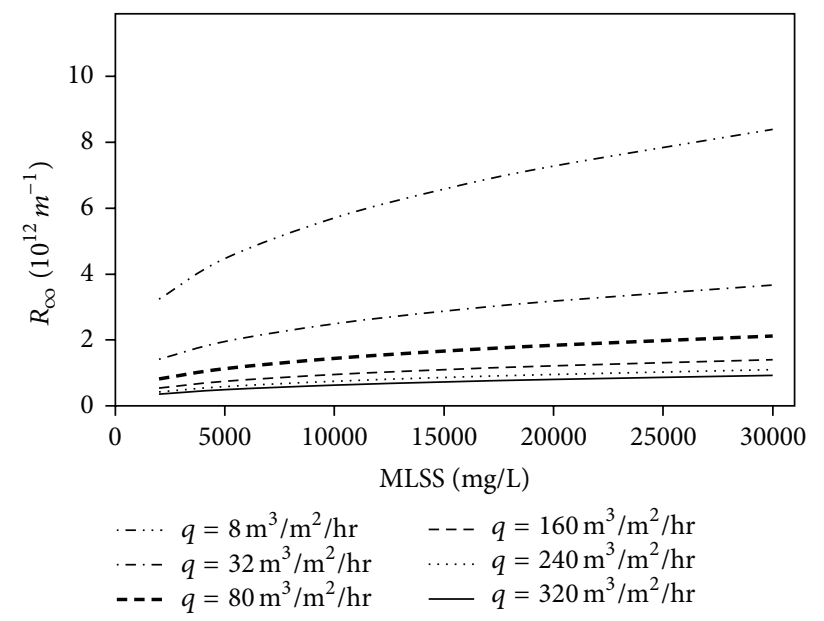

FIGURE 5: Ultimate filtration resistance as a function of MLSS concentration at various aeration intensities.

In order to generalize the proposed model, the parameters of the model, $R_{\infty}$ and $r_{R}$, were correlated to MLSS concentration and superficial air velocity by the following power law functions:

$$
\begin{gathered}
R_{\infty}=0.9429 \times 10^{8} X^{1.5402} q^{-0.3872}, \\
r_{R}=0.1250 \times 10^{8} X^{0.3513} q^{-0.5970},
\end{gathered}
$$

for which correlation coefficients of 0.9615 and 0.9856, respectively, were obtained by using the linear least squares regression method.

Figure 5 illustrates the ultimate filtration resistance $\left(R_{\infty}\right)$ of the system as a function of MLSS concentration at various aeration intensities, calculated based on (12). This figure shows that the resistance increases by increasing the MLSS concentration. At low superficial air velocity, the resistance is highly sensitive to the superficial air velocity, while it is not sensitive to the aeration rate at high superficial air velocity. In

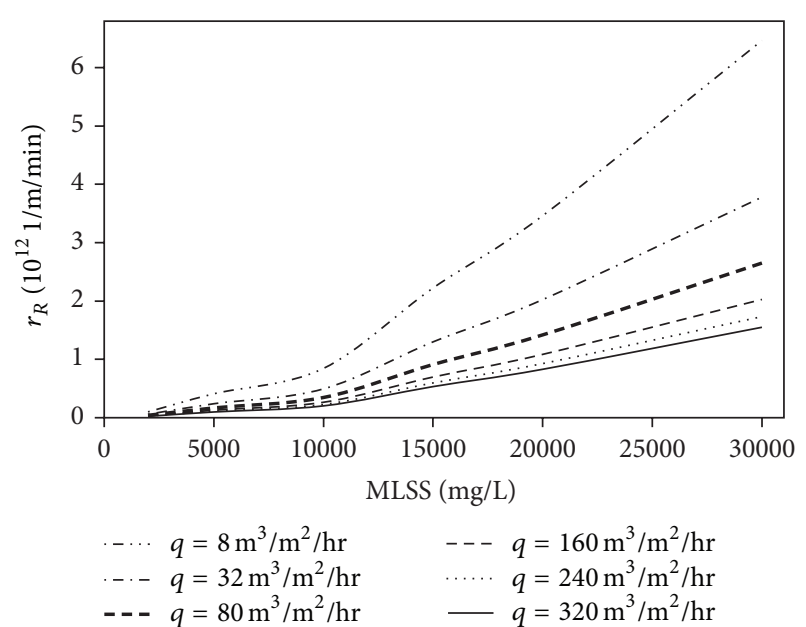

FIGURE 6: Initial rate of cake formation as a function of MLSS concentration at various aeration intensities.

fact, aeration removes deposited particles on the membrane surface and, consequently, prevents formation of cake. At a constant TMP, by increasing the superficial air velocity the process reaches an equilibrium condition at which increasing the superficial air velocity does not affect cake formation and filtration resistance. It is also observed in Figure 5 that the MLSS concentration has a negligible effect on the ultimate filtration resistance. In fact, when the cake on the surface of the membrane is formed completely, the process reaches the steady-state condition. At such a condition, the driving force (TMP) and resistance force (superficial air velocity) reach equilibrium so that by changing the MLSS concentration, the cake formed on the surface of the membrane does not change significantly. The value of $R_{\infty}$ thus becomes important when the system operates at steady-state condition.

Initial rate of cake formation $\left(r_{R}\right)$ corresponds to the tendency of fouling of the system. Figure 6 shows the effect of MLSS concentration on the initial rate of cake formation at various aeration intensities, calculated based on (13). As can be seen in this figure, the initial rate of cake formation increases rapidly by increasing the MLSS concentration. When the MLSS concentration is higher than $10000 \mathrm{mg} / \mathrm{L}$, the initial rate of the increase of cake formation is more significant. This trend may be explained by the fact that the tendency of cake formation increases at high MLSS concentration. In fact, increasing the MLSS concentration increases the aggregation of suspended particles on the membrane surface, thereby causing an increase in the cake formation rate. The initial rate of cake formation decreases sharply by increasing the superficial air velocity at low aeration intensities, while this change is not sensitive to the aeration rate at high aeration intensities. In fact, increase in superficial air velocity causes increment of the shear stress due to higher cross flow rate of fluid on the membrane surface. Shear stress is not a linear function of superficial air velocity; thus, increasing the velocity at high aeration rate has low effect on the shear stress and cake formation. The value of $r_{R}$ becomes 
important when the system is to be operated in short periods with frequent washing of the surface of the membrane.

\section{Conclusions}

A new model is proposed for the prediction of fouling in the iMBR based on cake formation on the membrane surface through constant pressure filtration process in which the reduction of the cake porosity is explained by intermediate blocking mechanism. The presented model can be applied to the prediction of membrane fouling of flat-sheet iMBRs which operate at constant pressure condition. The model includes two main parameters, that is, the ultimate filtration resistance and the initial rate of cake formation. These parameters were determined by fitting the experimental data of flow rate obtained from the beginning stage of the operation of the iMBR to the model. The value of $R_{\infty}$ indicates the ultimate fouling resistance and is important when the system is to be operated for a long time. The parameter $r_{R}$ is the initial fouling rate and is important when the system operates at short time and/or the surface of the membrane is washed frequently. The proposed model is in good agreement with other experimental data reported in the literature. This model can predict the fouling properly. It was also shown that the new model performs considerably better in the iMBR than other conventional fouling models at constant filtration pressure. The effect of MLSS concentration and superficial air velocity on the model parameters was studied. It was shown that the sensitivity of ultimate filtration resistance and initial rate of cake formation to the aeration rate at lower superficial velocity is more than that at higher aeration rate. It was also observed that the ultimate filtration resistance has a linear relation with MLSS concentration. By increasing the MLSS concentration, the initial rate of cake formation increases which causes increasing in the tendency of fouling. Future studies are necessary to improve this model to evaluate the effect of other operational parameters such as biological polymeric substances, HRT, and SRT.

\section{Symbols}

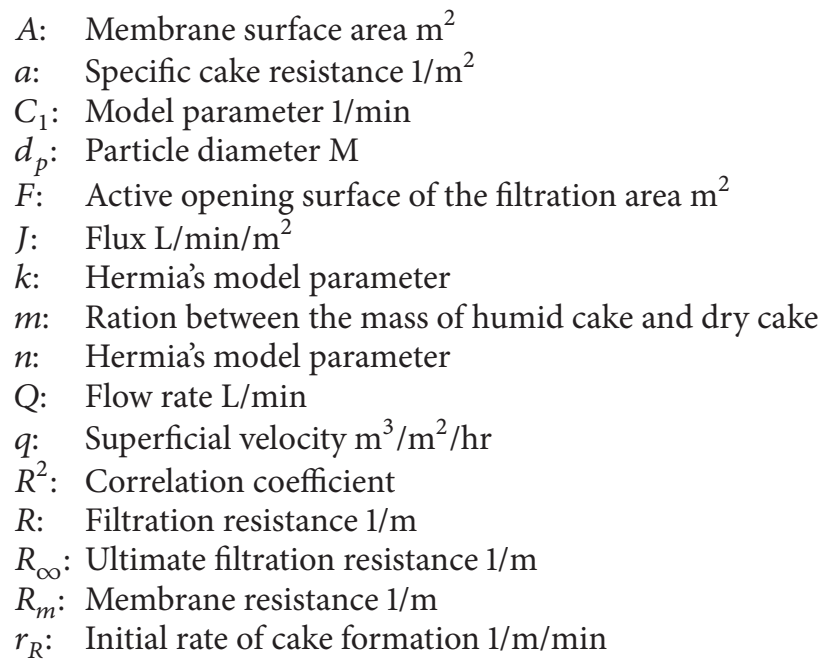

$t:$ Time per min

$V$ : Filtrated volume $\mathrm{L}$

$X$ : MLSS concentrations $\mathrm{mg} / \mathrm{L}$

\section{Greek Letters}

$\alpha: \quad$ Specific resistance of filtration cake $1 / \mathrm{m}$

$\sigma$ : Blocked area per unit filtrate volume $\mathrm{m}^{2} / \mathrm{m}^{3}$

$\triangle P$ : Trans-membrane pressure $\mathrm{Pa}$

$\mu: \quad$ Viscosity Pa.s

$\phi$ : Share of solid body in the filtrated suspension

$\rho:$ Density of cake $\mathrm{kg} / \mathrm{m}^{3}$.

\section{Acknowledgment}

This work was supported by a grant from the Isfahan Water and Wastewater Company, Iran.

\section{References}

[1] W. Khongnakorn, C. Wisniewski, L. Pottier, and L. Vachoud, "Physical properties of activated sludge in a submerged membrane bioreactor and relation with membrane fouling," Separation and Purification Technology, vol. 55, no. 1, pp. 125-131, 2007.

[2] J. Schaller, A. Drews, and M. Kraume, "Analyses and modelling of filtration processes in MBR and test cells," Desalination, vol. 199, no. 1-3, pp. 507-508, 2006.

[3] A. Zarragoitia-González, S. Schetrite, M. Alliet, U. JáureguiHaza, and C. Albasi, "Modelling of submerged membrane bioreactor: conceptual study about link between activated slugde biokinetics, aeration and fouling process," Journal of Membrane Science, vol. 325, no. 2, pp. 612-624, 2008.

[4] G. di Bella, G. Mannina, and G. Viviani, "An integrated model for physical-biological wastewater organic removal in a submerged membrane bioreactor: model development and parameter estimation," Journal of Membrane Science, vol. 322, no. 1, pp. 1-12, 2008.

[5] S. Rosenberger, C. Laabs, B. Lesjean et al., "Impact of colloidal and soluble organic material on membrane performance in membrane bioreactors for municipal wastewater treatment," Water Research, vol. 40, no. 4, pp. 710-720, 2006.

[6] D. P. Saroj, G. Guglielmi, D. Chiarani, and G. Andreottola, "Subcritical fouling behaviour modelling of membrane bioreactors for municipal wastewater treatment: the prediction of the time to reach critical operating condition," Desalination, vol. 231, no. 1-3, pp. 175-181, 2008.

[7] I. Martin, M. Pidou, A. Soares, S. Judd, and B. Jefferson, "Modelling the energy demands of aerobic and anaerobic membrane bioreactors for wastewater treatment," Environmental Technology, vol. 32, no. 9, pp. 921-932, 2011.

[8] C. C. Ho and A. L. Zydney, "Overview of fouling phenomena and modeling approaches for membrane bioreactors," Separation Science and Technology, vol. 41, no. 7, pp. 1231-1251, 2006.

[9] N. Ratkovich, C. C. V. Chan, P. R. Berube, and I. Nopens, "Experimental study and CFD modelling of a two-phase slug flow for an airlift tubular membrane," Chemical Engineering Science, vol. 64, no. 16, pp. 3576-3584, 2009.

[10] S. J. Judd, "A review of fouling of membrane bioreactors in sewage treatment," Water Science and Technology, vol. 49, no. 2, pp. 229-235, 2004.

[11] X.-M. Wang, X.-Y. Li, and X. Huang, "Membrane fouling in a submerged membrane bioreactor (SMBR): characterisation of 
the sludge cake and its high filtration resistance," Separation and Purification Technology, vol. 52, no. 3, pp. 439-445, 2007.

[12] P. Cornel, M. Wagner, and S. Krause, "Investigation of oxygen transfer rates in full scale membrane bioreactors," Water Science and Technology, vol. 47, no. 11, pp. 313-319, 2003.

[13] H. Dhaouadi and B. Marrot, "Olive mill wastewater treatment in a membrane bioreactor: process stability and fouling aspects," Environmental Technology, vol. 31, no. 7, pp. 761-770, 2010.

[14] A. N. L. Ng and A. S. Kim, "A mini-review of modeling studies on membrane bioreactor (MBR) treatment for municipal wastewaters," Desalination, vol. 212, no. 1-3, pp. 261-281, 2007.

[15] M. Spérandio and M. C. Espinosa, "Modelling an aerobic submerged membrane bioreactor with ASM models on a large range of sludge retention time," Desalination, vol. 231, no. 1-3, pp. 82-90, 2008.

[16] A. Khalili-Garakani, M. R. Mehrnia, N. Mostoufi, and M. H. Sarrafzadeh, "Analyze and control fouling in an airlift membrane bioreactor: CFD simulation and experimental studies," Process Biochemistry, vol. 46, no. 5, pp. 1138-1145, 2011.

[17] Y. Lee, J. Cho, Y. Seo, J. W. Lee, and K.-H. Ahn, "Modeling of submerged membrane bioreactor process for wastewater treatment," Desalination, vol. 146, no. 1-3, pp. 451-457, 2002.

[18] T. Jiang, S. Myngheer, D. J. W. de Pauw et al., "Modelling the production and degradation of soluble microbial products (SMP) in membrane bioreactors (MBR)," Water Research, vol. 42, no. 20, pp. 4955-4964, 2008.

[19] G. Mannina, G. di Bella, and G. Viviani, "An integrated model for biological and physical process simulation in membrane bioreactors (MBRs)," Journal of Membrane Science, vol. 376, no. 1-2, pp. 56-69, 2011.

[20] F. Meng, H. Zhang, Y. Li, X. Zhang, and F. Yang, "Application of fractal permeation model to investigate membrane fouling in membrane bioreactor," Journal of Membrane Science, vol. 262, no. 1-2, pp. 107-116, 2005.

[21] R. Liu, X. Huang, Y. F. Sun, and Y. Qian, "Hydrodynamic effect on sludge accumulation over membrane surfaces in a submerged membrane bioreactor," Process Biochemistry, vol. 39, no. 2, pp. 157-163, 2003.

[22] X.-Y. Li and X.-M. Wang, "Modelling of membrane fouling in a submerged membrane bioreactor," Journal of Membrane Science, vol. 278, no. 1-2, pp. 151-161, 2006.

[23] J. Hermia, "Constant pressure blocking filtration laws application to power law non newtonian fluids," Chemical Engineering Research and Design, vol. 60, no. 3, pp. 183-187, 1982.

[24] A. Drews, H. Arellano-Garcia, J. Schöneberger, J. Schaller, G. Wozny, and M. Kraume, "Model-based recognition of fouling mechanisms in membrane bioreactors," Desalination, vol. 236, no. 1-3, pp. 224-233, 2009.

[25] J. Busch, A. Cruse, and W. Marquardt, "Modeling submerged hollow-fiber membrane filtration for wastewater treatment," Journal of Membrane Science, vol. 288, no. 1-2, pp. 94-111, 2007.

[26] D.-W. Gao, Y. Fu, Y. Tao, W.-M. Wu, R. An, and X.-X. Li, "Current research and development of controlling membrane fouling of MBR," The African Journal of Biotechnology, vol. 8, no. 13, pp. 2993-2998, 2009.

[27] Q. Wang, Z. Wang, Z. Wu, J. Ma, and Z. Jiang, "Insights into membrane fouling of submerged membrane bioreactors by characterizing different fouling layers formed on membrane surfaces," Chemical Engineering Journal, vol. 179, pp. 169-177.

[28] L. Giorno, L. Donato, S. Todisco, and E. Drioli, "Study of fouling phenomena in apple juice clarification by enzyme membrane reactor," Separation Science and Technology, vol. 33, no. 5, pp. 739-756, 1998.

[29] K. Konieczny and J. Rafa, "Modeling of the membrane filtration process of natural waters," Polish Journal of Environmental Studies, vol. 9, no. 1, pp. 57-63, 2000.

[30] S. Rosenberger, H. Evenblij, S. Te Poele, T. Wintgens, and C. Laabs, "The importance of liquid phase analyses to understand fouling in membrane assisted activated sludge processes-six case studies of different European research groups," Journal of Membrane Science, vol. 263, no. 1-2, pp. 113-126, 2005.

[31] S.-H. Hong, W.-N. Lee, H.-S. Oh et al., “The effects of intermittent aeration on the characteristics of bio-cake layers in a membrane bioreactor," Environmental Science and Technology, vol. 41, no. 17, pp. 6270-6276, 2007.

[32] I. Ivanovic and T. O. Leiknes, "The biofilm membrane bioreactor (BF-MBR)-a review," Desalination and Water Treatment, vol. 37, no. 1-3, pp. 288-295, 2012.

[33] B. Tansel, W. Y. Bao, and I. N. Tansel, "Characterization of fouling kinetics in ultrafiltration systems by resistances in series model," Desalination, vol. 129, no. 1, pp. 7-14, 2000.

[34] APHA, Standard Methods for the Examination of Water and Wastewater, American Public Health Association, Washington, DC, USA, 17th edition, 1989.

[35] S. Mafirad, M. R. Mehrnia, H. Azami, and M. H. Sarrafzadeh, "Effects of biofilm formation on membrane performance in submerged membrane bioreactors," Biofouling, vol. 27, no. 5, pp. 477-485, 2011.

[36] V. T. Kuberkar and R. H. Davis, "Modeling of fouling reduction by secondary membranes," Journal of Membrane Science, vol. 168, no. 1-2, pp. 243-258, 2000. 


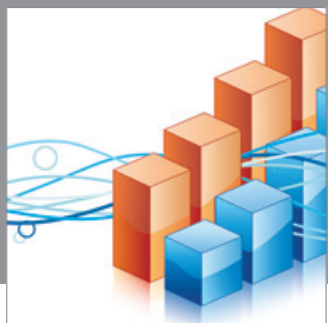

Advances in

Operations Research

mansans

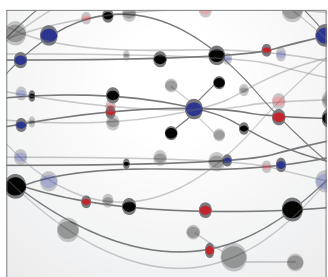

The Scientific World Journal
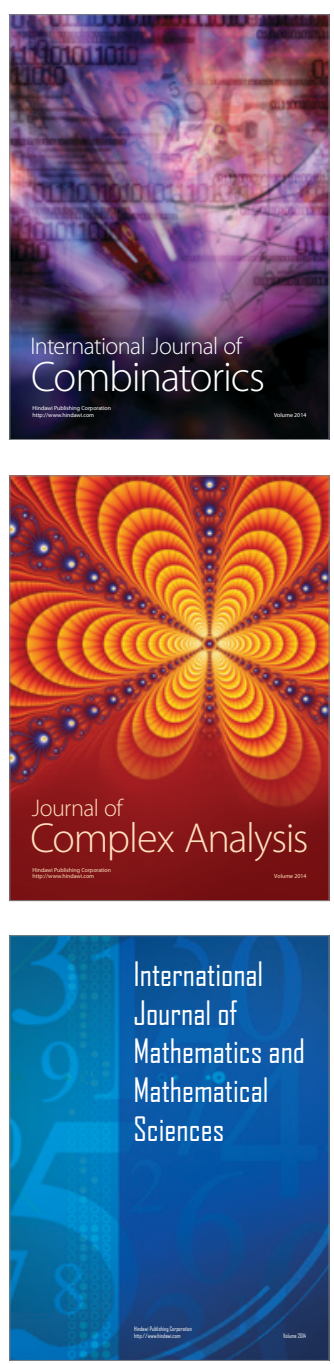
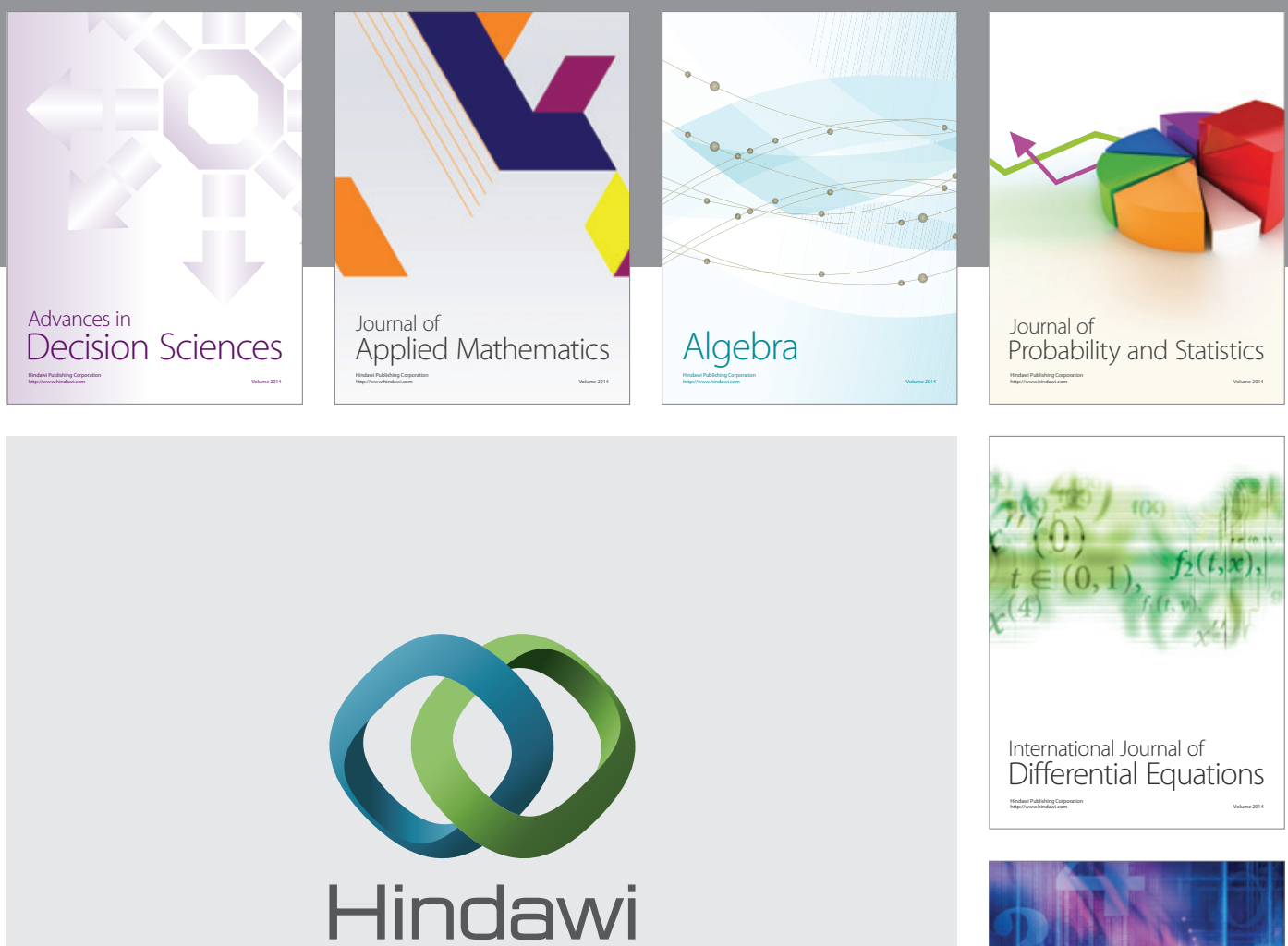

Submit your manuscripts at http://www.hindawi.com
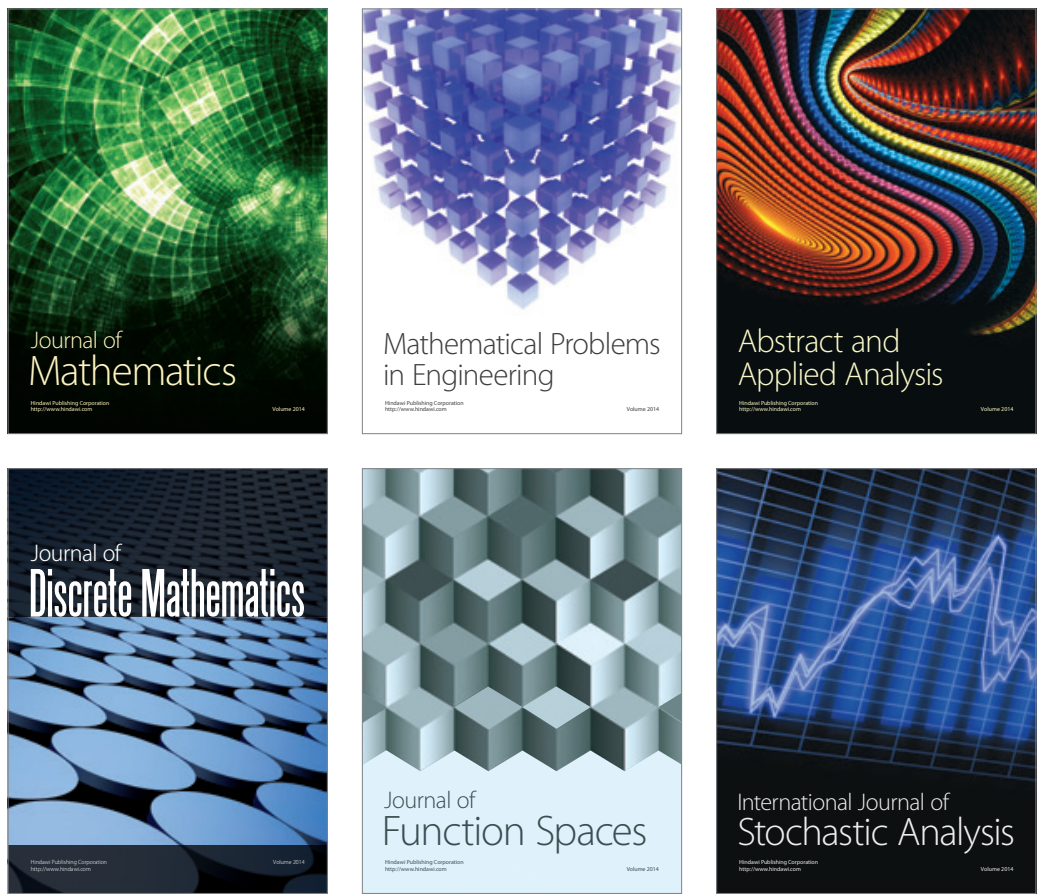

Journal of

Function Spaces

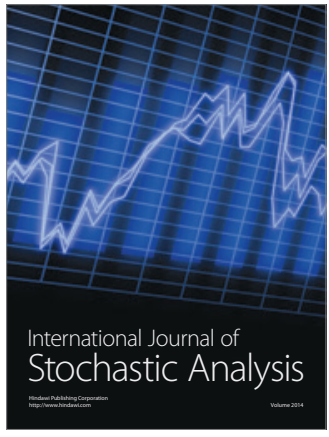

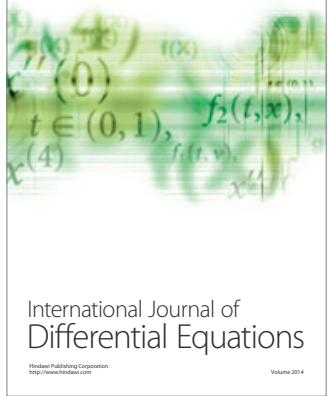
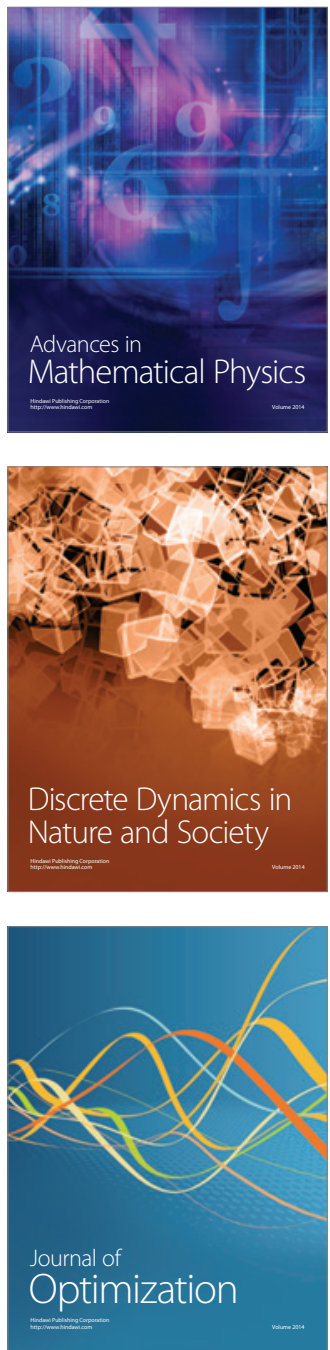